lubricating products not specifically designed for intercourse is common. The frequency and potential health effects of AI lubricants warrant further study.

\section{P2-S9.06 VAGINAL FILM MICROBICIDES FOR HIV PREVENTION: A MIXED METHODS STUDY OF WOMEN'S PREFERENCES}

doi:10.1136/sextrans-2011-050108.392

${ }^{1} \mathrm{M}$ Fan, 'L Ferguson, 'L Rohan, ${ }^{2} \mathrm{~L}$ Meyn, ${ }^{1} \mathrm{~S}$ Hillier. ${ }^{1}$ University of Pittsburgh, Pittsburgh, USA; ${ }^{2}$ Magee-Womens Research Institute, Pittsburgh, USA

Background Quick-dissolve films hold promise for HIV microbicide formulation with regards to low cost and scalable manufacture. Consideration of women's preferences enhances probable use of promising microbicides. This study examined preferred physical characteristics of quick-dissolve vaginal films for HIV prevention and factors that influenced valuation of HIV prevention.

Methods We conducted a cross-sectional mixed methods study of women aged 18-30 years from two counties in southwestern Pennsylvania to qualitatively and quantitatively assess preferences. During focus groups women handled and evaluated films of varying texture, thickness, size, shape, and appearance. A prefocus group survey collected demographics, sexual history, and valuation of vaginal product characteristics. A post-focus group survey collected attitudes towards vaginal microbicides. We carried out thematic analysis of focus group transcripts using modified grounded theory. We examined relationships between participant characteristics and valuing HIV prevention using Fisher's exact test.

Results Eighty-four women participated, with a mean age of 23 years and largely white (54\%) and black (43\%). Only three reported previous use of a vaginal film. Participants preferred films to be smooth and thin (63\%), translucent (48\%), and $2 \times 2$ " square size $(36 \%)$. Translucent and smooth, thin films were perceived as likely to disintegrate rapidly. Smooth, thin films were perceived as more comfortable and less irritating than textured, thick films. Translucent films were thought to represent a balance between discretion and visual discernibility. Easy, accurate insertion, uniform coverage, and adequate HIV prevention efficacy were viewed as advantages of $2 " \times 2$ " square size films. Engaging in at least one episode of binge drinking in the past year was associated with rating HIV prevention as important $(p=0.048)$. Participants expressed concern regarding sexual intercourse in the context of alcohol intoxication. Factors associated with ranking HIV prevention as the most important characteristic of a vaginal product included higher number of lifetime vaginal sex partners $(p=0.001)$ and black race $(\mathrm{p}=0.011)$

Conclusions Smooth, thin, translucent, and 2" $\times 2$ " square films were perceived to offer features valued by women in our sample. Women were concerned with issues of use, including insertion, disintegration, and comfort, as well as issues of discretion and efficacy.

\section{P2-S9.07 ECONOMIC RISK FACTORS FOR SYPHILIS INFECTION AMONG PREGNANT WOMEN IN RURAL HAITI}

\section{doi:10.1136/sextrans-2011-050108.393}

${ }^{1} \mathrm{~J}$ Mark, ${ }^{2} \mathrm{~L}$ Wesler, ${ }^{3} \mathrm{C}$ Oswald, ${ }^{2} \mathrm{~F}$ Léandre, ${ }^{2} \mathrm{P}$ Nevil, ${ }^{2} \mathrm{D}$ Bertrand, ${ }^{2} \mathrm{~J}$ Bertrand, ${ }^{3} \mathrm{~F}$ Boehm, ${ }^{3,4} \mathrm{M}$ C Smith Fawzi. ${ }^{1}$ Centers for Disease Control and Prevention Atlanta, USA; ${ }^{2}$ Zanmi Lasante Sociomedical Complex Cange, Haiti; ${ }^{3}$ Partners In Health Boston, USA; ${ }^{4}$ Harvard Medical School, Boston, USA

Background Of the 12 million global adult syphilis infections occurring globally each year, syphilis disproportionately affects women in low-income countries. WHO estimates about $80 \%$ of syphilis positive pregnancies go untreated, often in Latin America and Africa. Economic and socio-structural characteristics may explain some of the vulnerability for infection. We studied the association between social and health services factors and syphilis in Haiti, a poor country with a high burden of infection.

Methods We used data collected for a clinic-based case-control study of pregnant women attending general care women's clinics in rural Haiti from June 1999-to March 2001. Syphilis serostatus was determined by RPR test. Women were surveyed on socio-demographic and economic factors, access to healthcare, and sexual and gynaecological history. We performed multivariate analysis in SAS to identify factors associated with syphilis seropositivity and present results on two models.

Results The 596 women studied were typically young, rural, and lived in poverty. Syphilis and HIV seropositivity were $5.5 \%$ and $4.3 \%$, respectively. In model $1(n=396)$, factors associated with maternal syphilis infection were: household monthly per capita income $<75$ goud (\$20 USD) (OR 2.4, 95\% CI 0.9 to 6.6), having a 1 room house (OR 5.2, 95\% CI 1.6 to 17.0 ), and history of prior pregnancy resulting in premature birth (OR 5.1, 95\% CI 2.0 to 13.0) In model $2(n=417)$, having fields where family members plant crops was a protective factor (OR $0.26,95 \%$ CI 0.074 to 0.92 ), while reporting problems obtaining education (OR 3.2, 95\% CI 1.1 to 7.7 ), $<15$ years of age at first intercourse (OR 2.9, 95\% CI 1.1 to 7.7 ), history of an STD (OR=11.0, 95\% CI 3.2 to 40.0), and vaginal discharge with odour (OR 3.4, 95\% CI 1.1 to 11.0) were associated with maternal syphilis infection see Abstract P2-S9.07 Table 1.

Discussion Among pregnant women in Haiti, some economic characteristics were predictors of vulnerability for syphilis infection and may help explain the inequitable distribution of syphilis disease burden. Further study is warranted to understand specific economic or other structural factors that may affect syphilis infection in women and may be amenable to intervention.

Abstract P2-S9.07 Table 1 Multiple logistic regression analysis of factors associated with maternal syphilis status of women in rural Haiti

\begin{tabular}{|c|c|}
\hline & OR $(95 \% \mathrm{CI})$ \\
\hline \multicolumn{2}{|l|}{ Model $1(n=396)$} \\
\hline Monthly per capita income less than 75 goud/person & $2.4(0.9$ to 6.5$)$ \\
\hline House has 1 room only & $5.2(1.6$ to 17.0$)$ \\
\hline$\leq 15$ years old at first sexual intercourse & $1.8(0.7$ to 4.5$)$ \\
\hline History of premature birth & $5.1(2.0$ to 13.0$)$ \\
\hline \multicolumn{2}{|l|}{ Model $2(n=417)$} \\
\hline Has fields where family members plant crops & $0.26(0.1$ to 0.9$)$ \\
\hline House has 1 room only & $1.6(0.4$ to 6.3$)$ \\
\hline Has problems with education & $3.2(1.1$ to 9.3$)$ \\
\hline$\leq 15$ years old at first sexual intercourse & $2.9(1.1$ to 7.7$)$ \\
\hline More than 1 lifetime sexual partner & $1.1(0.4$ to 3.2$)$ \\
\hline $\begin{array}{l}\text { Had sexual intercourse with someone she knows or } \\
\text { suspects had an STD }\end{array}$ & $2.9(0.3$ to 30.0$)$ \\
\hline History of an STD & 11 (3.2 to 40.0$)$ \\
\hline Vaginal discharge with a bad smell & $3.4(1.1$ to 11.0$)$ \\
\hline Travels to clinic or health center by bus & $1.8(0.6$ to 5.3$)$ \\
\hline $\begin{array}{l}\text { Has more difficulties getting to usual health center or } \\
\text { clinic during rainy season compared to dry season }\end{array}$ & $0.4(0.2$ to 1.2$)$ \\
\hline
\end{tabular}

\section{P2-S9.08 BABY DADDY SEX AS A RISK FACTOR FOR HIV/STDS}

doi:10.1136/sextrans-2011-050108.394

P Padgett, J Risser. University of Texas School of Public Health, Houston, USA

Background Concurrent sexual relationships increase the likelihood of exposure to HIV/STDs. Sexual patterns among poor urban 